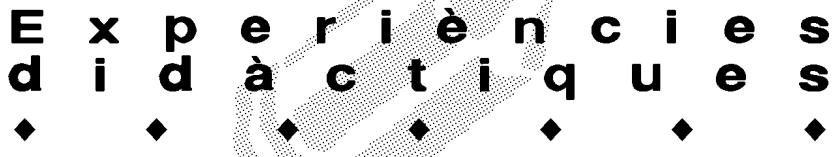

\section{PENSAMENT PEDAGÒGIC I ACCIÓ EDUCATIVA DE ZOLTÁN KODÁLY}

\author{
Enriqueta Barniol. Àrea de Didàctica de l'Expressió Musical
}

\section{Preludi}

L'educació, en la seva permanent recerca de recursos per millorar i renovar els mètodes d'ensenyament/ aprenentatge de les ciències, les lletres i les arts, ha estat en un continu procés d'experimentació i de renovació. L'educació musical no ha estat cap excepció d'aquesta norma. La realitat que ens envolta i el moment històric present imposen que l'educació musical arribi a tothom, a través de la música viva i com a experiència de valors estètics i socials.

La música s'ha anat integrant de mica en mica en el currículum escolar de la majoria de països fins al punt que avui ja queda reflectida en el currículum del nostre nou Sistema Educatiu (LOGSE).

L'educació musical cal entendre-la no solament com la capacitació per percebre el missatge musical, sinó com un important element de la formació integral de la personalitat. Amb una planificació i una estructuració de l'educació musical ja des de ben petit, es potencia la cultura musical de l'adult i, en conseqüència la de tota la societat.

De totes les experiències portades a terme en els últims anys en el camp de l'educació musical, destaca el sistema d'educació musical Kodály.

Zoltán Kodály (1882-1967), nascut a Kecskemét (Hongria), es va distingir com a compositor (creant una obra de valor clàssic, impregnada de melodies populars i ritmes característics del seu país), musicòleg (fou pioner en la investigació i recopilació del folklore hongarès), pedagog (va realitzar un sistema d'educació musical, establint una progressió de coneixements a partir de la cançó popular), lingüista (es va preocupar de defensar la llengua i cultura hongaresa) i polític cultural (realitzant publicacions científiques, crítiques musicals...).

Va dedicar gran part de la seva activitat artística a l'educació musical del poble hongarès i al foment de la cultura musical. Pels volts de 1925 centrava la seva atenció en la pedagogia musical desenvolupant un concepte músico-educatiu que pretenia posar la música a l'abast de tothom i fer del poble hongarès el més músic possible: creia que no tan sols els dotats, sinó tothom pot aprendre, entendre i apreciar la música.

És un dels músics més eminents de l'escola hon- garesa contemporània, juntament amb Bela Bartok (1881-1945). L'aparició, a principis del segle XX, dels dos músics, que es van consagrar amb passió a renovar la música dels seu país, va revolucionar la vida musical d'Hongria, que s'allunyà progressivament de la influència unilateral de la música alemanya.

\section{Principis pedagògics}

El mal anomenat mètode Kodály no és una novetat en el camp de la pedagogia musical, en el sentit que tot el que treballa és nou; el treball de Kodály consisteix a haver organitzat amb criteri lògic $i$ coherent tots els aspectes didàctics, precisant-ne els seus objectius $\mathrm{i}$ plantejaments amb àmplia visió educativa. És una filosofia que parteix de la pràctica per extreure'n la teoria, i que defensa que tots els nens tenen dret a una educació musical.

Els seus principis pedagògics no es limiten tan sols a una experiència sonora $0 \mathrm{a}$ un mètode per aprendre música, sinó tot al contrari: a més d'ensenyar la destresa instrumental, implica un grau d'agudesa auditiva molt gran i una interpretació musical molt conscient. Va trobar les fonts de la música popular hongaresa, les va integrar en el seu sistema i les va utilitzar com a mitjà per aconseguir els fins educatius. Kodály va lluitar contra l'analfabetisme musical del seu país i va reformar Hongria, musicalment parlant. Va voler que la música no solament formés els futurs músics professionals, sinó també el poble, i que fos accessible a tothom. Desitjava un ensenyament educatiu que pogués produir una gent per a la qual la música no fos una manera de guanyar-se la vida, sinó una manera de viure. Volia veure un sistema d'educació musical desenvolupat a Hongria, capaç d'orientar els nens de cara a conèixer i estimar la música des dels primers anys d'escolarització fins a les etapes adultes. "...La música és una part indispensable de la cultura humana universal. Aquells que no posseeixin coneixements musicals tenen un desenvolupament intel.lectual imperfecte. Sense música no existeix home complet, integral. Per això és absolutament natural que la música s'integri al currículum escolar..." (Discurs pronunciat en la inauguració de la Casa de la Cultura de Dunapataj, el 1966). 


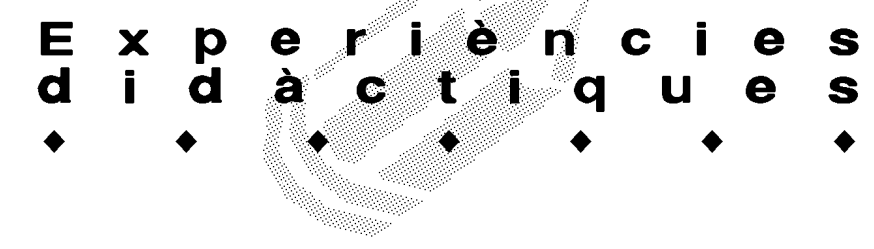

Segons Hanshumake (1980): "El sistema d'ensenyament musical Kodály té un efecte positiu sobre el desenvolupament general intel/lectual dels nens en edat escolar». Les investigacions demostren que un model d'ensenyament musical estructurat, que apunta al desenvolupament del pensament inductiu, afavoreix a partir de les generalitzacions que se'n desprenen (el traspàs d'aprenentatge). En aquest cas, l'ensenyament de la música segons els principis de Kodály és una font de traspàs d'aprenentatge.

Hongria pot valorar els resultats de la pedagogia de Kodály observant com un nombrós públic assisteix als concerts i vibra en contacte amb l'art musical. Internacionalment és centre de primer interès en l'àmbit de la pedagogia musical: ha estat adaptat àmpliament arreu d'Europa i Amèrica. El juliol de 1964, I'ISME (Societat Internacional d'Educació Musical) va celebrar el seu congrés a Budapest i va posar l'educació musical hongaresa com un exemple digne de ser seguit pels pedagogs d'arreu del món, amb la constatació dels espectaculars resultats obtinguts en les diferents etapes de l'escolaritat obligatòria.

Cal afegir a tot això que, arran de l'alliberament d'Hongria el 1945, el govern va fer seva la causa de l'educació musical en vista de l'èxit que van assolir les experiències de Kodály, i va adoptar oficialment el sistema per a l'educació musical del país amb la creació i l'extensió d'una xarxa d'ensenyament estatal de música.

\section{Un sistema d'ensenyament ben vertebrat}

Més que un "mètode", és una filosofia sobre la importància de la música en la vida del nen, de l'adolescent i de l'adult, que es fonamenta en els següents criteris:

- La integració de la música en l'ensenyament general, l'organització centralitzada de les activitats musicals, el material pedagògico-musical $i$ els seus llibres de text.

- Comporta en si mateix una vertadera i autèntica planificació, seleccionant les matèries de cada nivell de forma simple i progressiva, però a la vegada estricta i concisa.

- Posa la música a l'abast del nen des dels primers anys, adaptant-se de forma gradual i progressiva a la seva capacitat. Les experiències musicals estan disposades en una estructura que segueix les fases normals del creixement del nen.

- L'ordre pedagògic de cada experiència d'aprenentatge va del so a la visió i del concret a l'abstracte.

- La consideració de la veu humana com l'instrument més accessible a l'home i com el millor mitjà per estudiar i apreciar la música, perquè és el més important de tots els mitjans d'expressió musical i suposa endemés un grau d'agudesa auditiva molt gran i una interpretació musical molt conscient. Encara que mai hagi après a tocar un instrument, el nen haurà adquirit els millors i més excel-lents mitjans per captar i apreciar la música.

\section{Pocediments}

CANT

La pràctica del cant constitueix l'activitat principal, i d'aquesta pràctica el sistema en deriva totes les altres activitats, coneixements $\mathrm{i}$ experiències musicals que formen el currículum musical. Tant si s'utilitza la petita percussió en classes elementals com si més endavant es fa servir la flauta de bec, l'essencial és la veu.

El principal material per a les activitats i experiències musicals és:

1) El repertori popular de cançons del lloc autòcton, ja que hi trobem els esquemes rítmics i melòdics que les persones identifiquem i percebem com quelcom natural i de fàcil accés (exemple: cançó popular catalana Pedra, pedreta).

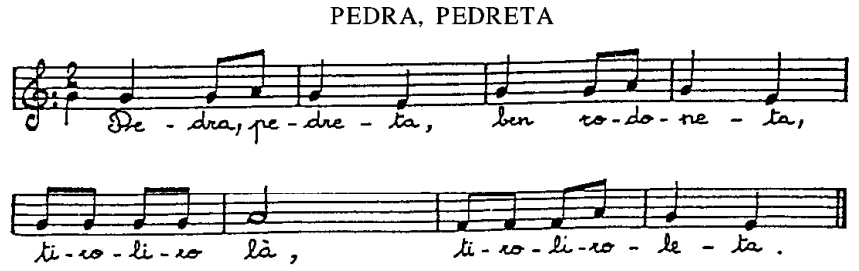

2) Repertori popular d'altres països; a mesura que es va assumint la progressió pedagògica, es pren repertori d'altres països per ensenyar un o altre element rítmic, melòdic o harmònic que no es troba pas dins el folklore propi (exemple: cançó Mireu els meus ànecs).

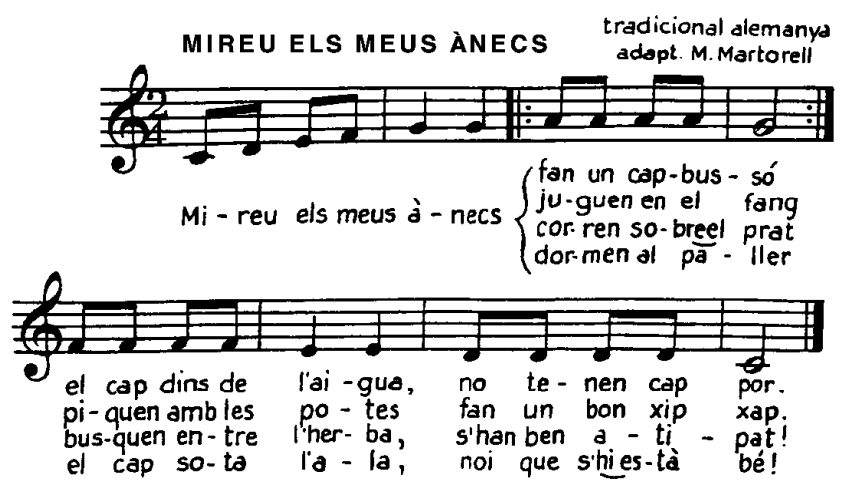

3) Simultaneïtat de cançons populars i de fragments d'obres de la literatura musical, per portar l'alumne a descobrir la gran música i perquè hi retrobi dins aquesta 


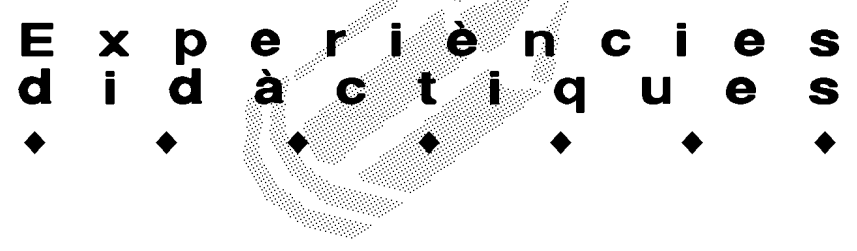

música els mateixos elements tècnics descoberts dins la cançó.

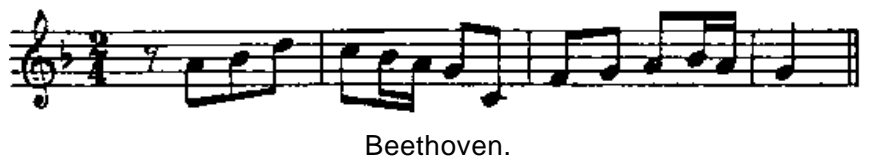

Kodály deia que la cançó popular és la llengua materna musical del nen, i de la mateixa forma que aprèn a parlar, l'ha d'aprendre essent molt petit. Naturalment, per als nens petits aquesta llengua materna és la música popular i la seva educació musical s'hi ha de basar. Per tant, el primer consisteix a confeccionar un llistat de cançons on s'incloguin moltes cançons infantils i populars, per elegir aquelles més idònies per als nens $\mathrm{i}$ poder utilitzar-les com a punt de partida per a la seva formació. Es tracta que trobin la tercera menor descendent sol-mii sol-la-mi (la com a nota auxiliar del sol), ja que aquests motius constitueixen els més familiars i freqüents en les cançons infantils. A més a més, els intervals de tercera són més interessants musicalment que una escala progressiva ascendent o descendent, i així progressivament fins a arribar a la diatonia $\mathrm{i}$ al cromatisme.

\section{POLIFONIA}

Aquelles persones que sempre canten a l'uníson mai no aprenen a cantar amb el to correcte. Només es pot aprendre a cantar a l'uníson cantant a dues veus: les veus s'ajunten l'una amb l'altra i mantenen l'equilibri. El primer pas per al desenvolupament del sentit polifònic el constitueix l'obstinat.

Cal que el nen senti l'efecte sonor i musical de la superposició des de ben aviat, i ho farà amb la percussió d'un obstinat rítmic en una cançó senzilla i en resultarà un primer pas cap al treball a veus (en aquest cas a dues veus). Més tard farem servir la forma "resposta" per passar a les polirítmies més complexes. El cànon serà el pas següent.

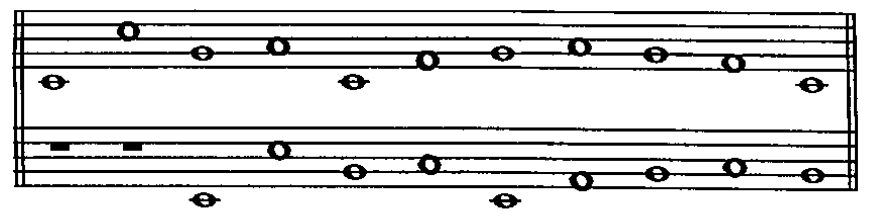

Cànon.

Per habituar els nens a cantar un so, sentint-ne un altre, Kodály va compondre una sèrie d'exercicis de cultura vocal a dues veus per equilibrar dues línies melòdiques i afavorir la justesa de l'afinació: "Cantem correctament". Els exercicis, molt simples, permeten a l'oïda de gravar lentament un seguit d'acords a dues veus i preparar directament el cant a dues veus.
Sempre pensant en la qualitat d'aquests textos musicals, Kodály va seleccionar algunes melodies populars hongareses, que ell va enriquir ajuntant-hi una segona veu (Bicinia Hungárica) on reparteix entre les dues veus la melodia popular pròpiament dita i va passant-la d'un cantó a l'altre alternativament del soprà al contralt i del contralt al soprà. I per augmentar de nivell va compondre els Tricínia Hungàrica per treballar a tres veus.

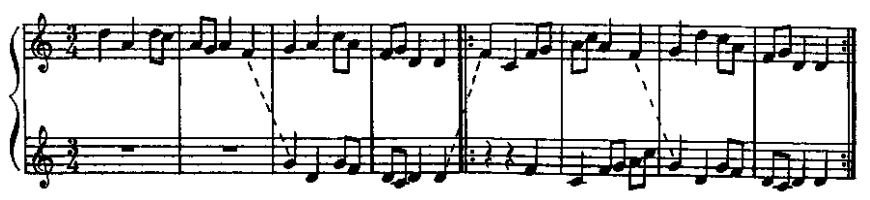

Fragment de Tricínia Hungàrica.

\section{La Pentatonia}

És un sistema de cinc notes diferents situat dintre de l'octava, que no incorpora cap interval disminuït ni augmentat ni la segona menor.

La pentatonia anhemitònica, la trobem en les cançons populars de cultures molt diverses. Les estructures melòdiques d'aquest sistema pentatònic són molt clares i molt simples. "... Una de les raons principals del fracàs de l'ensenyament de cant a la nostra escola és l'acumulació de dificultats. De sobte les complicacions de ritme ide to agafen el nen completament desprevingut, i n'hi ha pocs que puguin amb elles...El problema més gran de l'entonació és el semitó...les melodies pentatòniques són interessants i tenen varietat...i es poden cantar amb perfecta claredat. Quan el nen sap moure's per dintre d'aquest sistema, la introducció del semitò ja no serà difícil...» (Kodály, 1943).

És per això que la pràctica vocal variada de la pentatonia pot posar els fonaments d'una entonació segura, sobre els quals més endavant serà possible construir la diatonia de set graus o escala diatònica de set notes; i més endavant hi afegirem les notes alterades.

El Solfeig Relatiu

El solfeig relatiu fa servir els següents recursos:

1) La solmització: es fa servir a l'inici de l'ensenyament musical dels principiants. Consisteix en un plantejament didàctic i metodològic que permet des dels primers moments de la pràctica cantar qualsevol melodia sense clau, respectant la distància intervàlica, sigui quin sigui el seu sistema modal, tonal o atonal. S'aprenen sense clau ni tonalitat prèvia els intervals i distàncies de les notes a través de noms relatius: $d, r, m, f, s, l$, ti, per més endavant substituir tots aquests conceptes intuïtius per conceptes racionals: nom absolut de les notes $A, B$, $C, D, E, F, G, H$, moment en què es racionalitzaran les claus i les tonalitats escrites.

Facilita l'afinació i el cant a primera vista. Els intervals 


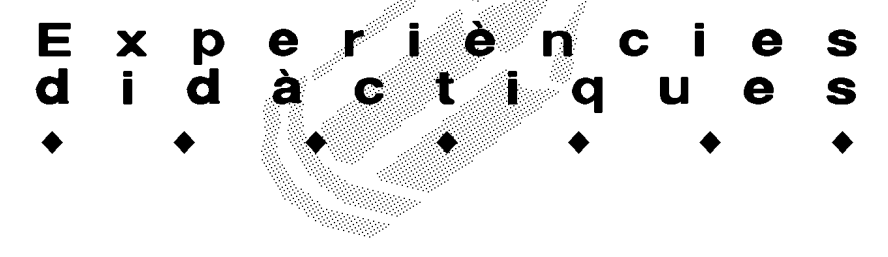

són sempre iguals i els nens es familiaritzen i fixen la distància intervàlica dibuixada i en la seva afinació corresponent. El nen es guia per distàncies sonores visuals

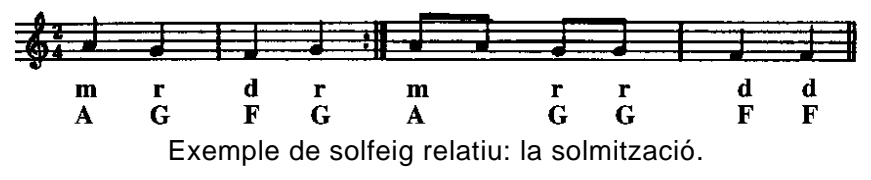

o d'oïda que el permetin intuir l'altura sonora de les notes escrites al pentagrama sense clau ni tonalitat. Assimilades les distàncies sonores, la rapidesa d'aprenentatge es duplica. Qualsevol que sigui la tonalitat en què està escrita la partitura, la tònica es llegeix sempre com doper a les tonalitats majors i la per a les tonalitats menors.

2) La nota solta: es fixa la representació d'una nota en l'extrem d'un pal i amb ella el mestre indica la progressió melòdica d'una frase musical sobre un pentagrama en blanc.

3) El "do" mòbil: seria una modificació posterior a l'anterior, que serveix per assignar diferents posicions al "do" sobre el pentagrama per indicar la primera nota d'una melodia o un exercici.

El Solfeig Absolut

Aquest és el solfeig que coneixem. És l'estudi del nom i del so de les notes, i per tant és la capacitat de cantar qualsevol melodia en la seva clau corresponent, sigui quin sigui el seus sistema tonal modal o atonal.

Fonemes Rítmics

Aquests fonemes únicament es fan servir a les primeres etapes de l'educació musical, ja que són una ajuda per vèncer les dificultats del començament.

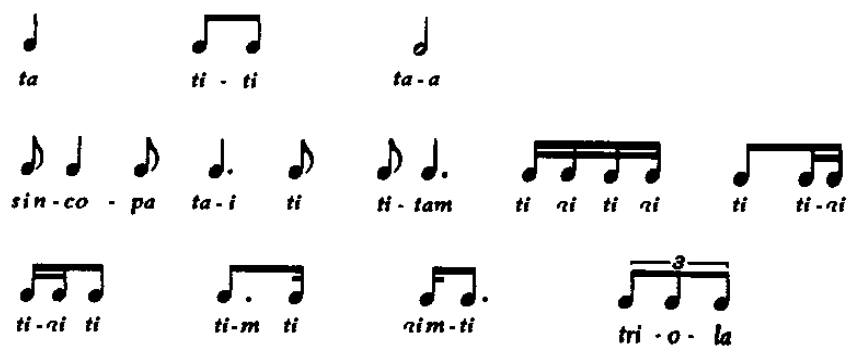

Alguns exemples de fonemes rítmics.

\section{LA FONOMÍMIA}

La fonomímia (signes musicals de les mans) no fou una creació personal de Kodály, sinó de John Spencer Curwen (1816-1880), que va introduir un sistema de signes manuals que simplificava la lectura de la partitura. Kodály hi va introduir alguns canvis. És un recurs per representar els sons musicals mitjançant la figura que se li doni a la mà i l'altura a què es posi, i visualitzar-los a l'espai. Cantar a partir de signes de mà es un mitjà útil i necessari per a l'aprenentatge intuïtiu i fixació de les relacions intervàliques fins que l'associació entre la música impresa i el nom esdevingui automàtica; educa inconscientment el nen en una afinació interna auditiva correcta i s'aferma a través dels gestos de la mà l'efecte del solfeig relatiu. Té un doble objectiu: per una banda, és una preparació per a les estructures melòdiques i els intervals que han d'aparèixer en el material musical de les lliçons, i per l'altra, desenvolupa el so del sistema tonal pentatònic de la manera més segura possible mitjançant la pràctica intensiva de diverses frases pentatòniques.

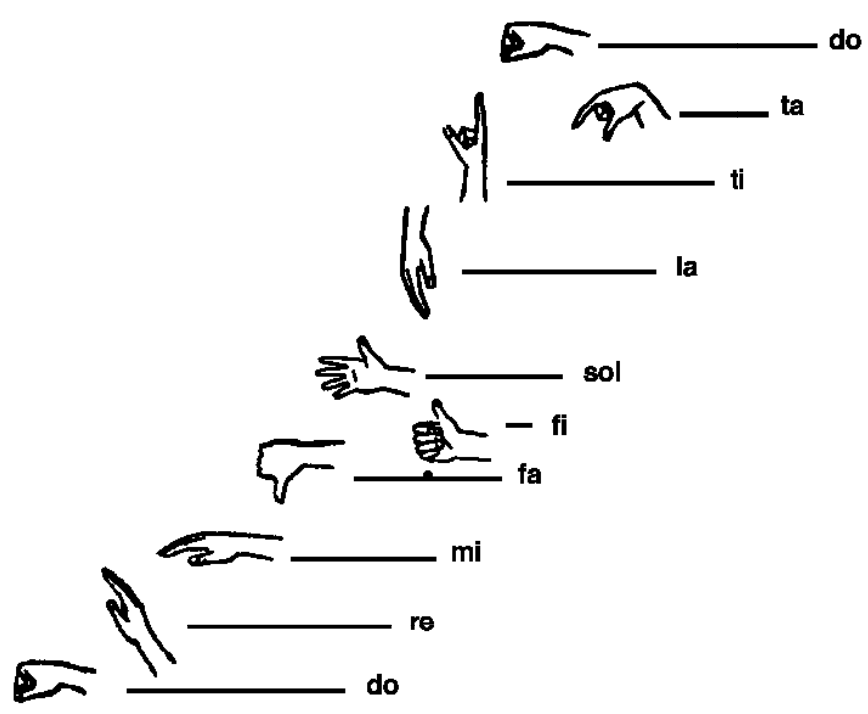

Signes musicals de les mans: La fonomímia.

Desenvolupament De La Memòria Musical

Desenvolupar la memòria musical és de la màxima importància, perquè els records musicals que existeixen en la nostra consciència, sobretot aquells que es van emmagatzemar tot cantant, són els mitjans més importants per desenvolupar l'oïda interna. Fins que els estudiants no assoleixin cert grau d'habilitat per cantar no "sentiran" d'una manera automàtica, sinó gràcies a analitzar la seva memòria musical. Aconseguiran afinar tot el que veuen escrit i escriuran tot el que senten. Facilitarà la fixació de les relacions i combinacions melòdiques i ajudarà a desenvolupar la facultat de visualitzar i escriure una melodia escoltada llarga i complexa. La repetició de les estructures melòdiques, rítmiques, harmòniques i formals porta al coneixement progressiu dels caràcters de la música culta, els seus compositors i els seus estils. 


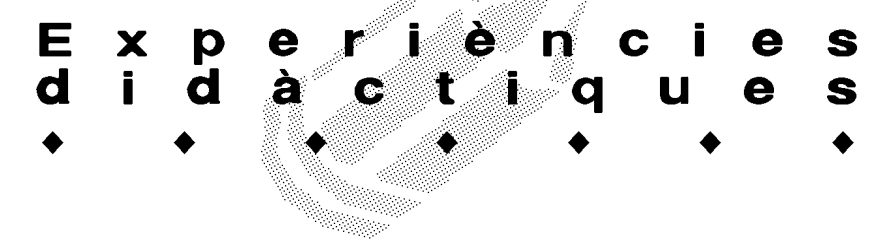

AUDICIÓ INTERIOR

És la facultat d'imaginar, representar i cantar mentalment la música. L'audició interior és indispensable i va lligada amb altres facultats anteriors: memorització, fonomímia, solfeig relatiu... Escoltar i sentir interiorment és més subtil que cantar o escriure la música que s'escolta. El més alt nivell d'audició interior s'adquireix quan l'alumne analitza una partitura d'orquestra i pot sentir l'obra interiorment, o quan un músic compon en el paper sense tocar el que estar escrivint.

La ImPRovisació I La CREACIÓ

La improvisació estimula la creació i la imaginació, al mateix temps que ajuda a descobrir les possibilitats de la música, facilitant l'assimilació del llenguatge musical.

Els nens aprenen a crear música per si mateixos $\mathrm{i}$ no solament a interpretar-la. Mentre que la improvisació és lliure i espontània, la creació o composició segueix essent lliure però sota una idea prèviament pensada $i$ ordenada. El primer pas serà el de "pregunta-resposta".

La Representació Dels Sons

La representació dels sons es sistematitza emprant els següents procediments:

- Escriptura pentagramal, que és l'escriptura tradicional de la música.

- Escriptura rítmico-lineal, que és un recurs per facilitar el solfeig; la seva pràctica s'ha de fer de forma paral-lela amb l'anterior escriptura.

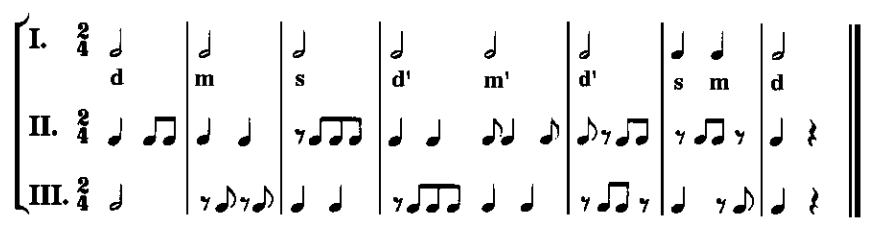

Exemple de representació dels sons.

\section{CAdena}

On cada alumne individualment ha de passar-se una fórmula rítmica i/o melòdica inventada pel professor o per un dels companys de classe. És en certa forma una pregunta-resposta continuada, però que en ser en petits grups o individual, suposa un treball molt important de regularitat i de precisió en la relació pulsació-ritme i en la justesa de l'afinació. Els ecos (imitació), que consisteix a fer preguntes-respostes de fórmules rítmiques i/o melòdiques de quatre o més pulsacions amb so. No solament ens permet una execució o realització sonora, sinó que també ens facilita una explicitació i una traducció verbal.

\section{CARTRONS}

Cartrons de cartolina o feltre amb pentagrames dibuixats i petites notes del mateix material de diversos colors, per a la pràctica de dictats melòdics i rítmics i creació de petites composicions que posteriorment seran cantades i traslladades al paper.

Durant el procés d'ensenyament, els diversos apartats (presentats aquí com unitats separades) constitueixen una unitat permanent $i$ un lligam indispensable en el progrés de cada planificació, de tal manera que l'alumne sent correctament la música, escriu el que acaba de cantar o d'escoltar, sent interiorment el que llegeix i canta o toca una part, tot i escoltant una altra part a la vegada.

\section{CODA: Una experiència musical i una recerca peda- gògica}

En les diferents especialitats d'ensenyament de mestre a la Universitat Rovira i Virgili hem fonamentat algunes de les matèries adscrites a l'àrea de Didàctica de l'Expressió Musical en el model d'ensenyament musical Kodály.

Els eixos vertebradors que han permès el disseny $\mathrm{i}$ desenvolupament del projecte docent que es fonamenta en el sistema d'ensenyament Kodály s'emmarquen en una formació pedagògico-musical a Hongria; indubtablement el gran interès que ofereix el fet d'efectuar un estudi en profunditat de les motivacions que van conduir els espectaculars resultats de l'educació musical a Hongria ens han permès:

- Aprofundir en la coneixença de les idees pedagògiques de Kodály i l'estructura del seu sistema d'educació musical al país, per comprendre millor com adaptar aquests principis al tarannà musical de les nostres cançons. L'experiència d'educació musical a Hongria, viscuda allà mateix, difícilment podrà ser igualada ni oblidada.

- Impregnar de petits detalls personals aquestes grans línies pedagògiques en l'aplicació a la nostra escola.

- Un compromís permanent en aquest aprendre i actualitzar-se sempre en el difícil art de l'Educació Musical.

Pel que fa a la realitat educativa de l'escola, ens ha permès:

- L'adaptació d'aquesta pedagogia Kodály al folklore català: tal i com volia Kodály, adequar l'essència de la seva pedagogia a la manera de ser del lloc on es vulgui introduir i practicar, ja que cal respectar la tradició musical de cada poble: coneixent les característiques rítmiques i melòdiques de la cançó popular catalana (tradicional, religiosa i culta), i tot seguit establint una progressió pedagògica basada en aquestes cançons. 


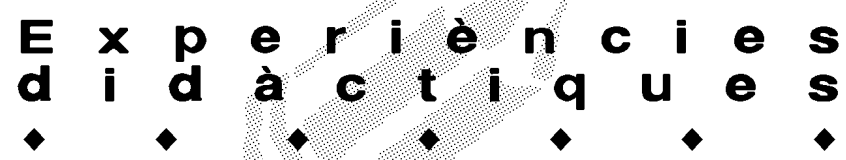

- L'experimentació d'aquest sistema en dos centres escolars d'educació infantil i primària, on hem treballat durant molts anys amb aquest sistema i hem aconseguit que no hi haguessin nens al-lèrgics a la música, que els nens cantessin amb naturalitat a dues veus; observant en aquests nens l'atenció i estima que tenen per la música; i l'emoció i interès que senten per interpretar cantates amb la participació de tot el centre i no només d'uns quants seleccionats; i finalment, que la música no és només una assignatura ornamental sino que té vida pròpia en el projecte curricular del centre, facilitant l'educació global del nen.

\section{Investigació i formació del professorat}

Tot i que la didàctica de la música és un camp de coneixement relativament jove en l'àmbit de la investigació, les recerques i projectes de treball que actualment realitzem a l'Àrea de Didàctica de l'Expressió Musical es concentren en la formació inicial i permanent del professorat.

Amb aquesta experiència hem pogut constatar que moltes de les nostres qüestions troben les seves respostes dins la concepció de l'educació musical Kodály i la seva estructuració a Hongria. Certament que a part d'aquest sistema d'ensenyament hi ha d'altres "mètodes" amb resultats notables, però la majoria d'ells es fonamenten d'alguna manera en molts punts pedagògics que Kodály va establir en el seu sistema. Enfront de nous "mètodes" o sistemes que puguin aparèixer, l'ensenyament musical Kodály seguirà essent el clàssic innovador, pioner i font d'inspiració per a tots i cadascun dels "mètodes" que a posteriori el vulguin emular.

Sempre hi ha bo, millor i òptim; de moment considerem que Kodály, en relació a altres metodologies, no direm que sigui òptim, però sí que és millor.

\section{Bibliografia consultada}

BARNIOL, E. L'educació musical a Hongria. «Revista Musical Catalana», 49 (1988) 28-33.

BARNIOL, E. Didàctica de l'expressió musical. Servei Lingüístic. Universitat Rovira i Virgili ed., s.v. Zoltán Kodály: el sistema d'educació musical hongarès, 19-25.

CHOMSKY, L. The Kodály Method: Comprhensive Music Education from Infant to Adult. Editorial Prentice Hall. New York.1974.

HANSHUMAKER, J. The effect of Art Educational on Intellectual and Social Development: A Review of selected Research. «Bulletin of the Council for research in Music Education», 51 (1980) 24.

KODÁLY, Z. «Visszatekintés I», (1943) 133.

$L$ 'enseignement musical en Hongrie et le developpement phisique et intellectuel de l'enfant. "Cahiers Pédagogiqques», 72 (1968) 12-19.

MANGIONE, G. La pedagogia della musica secondo Zoltán Kodály. (Florence: Ceccherini, 1974).

SINOR, J. Musical Development of Children and Kodály Pedagogy. «Kodály Envoy» 6 (1980) 6-10.

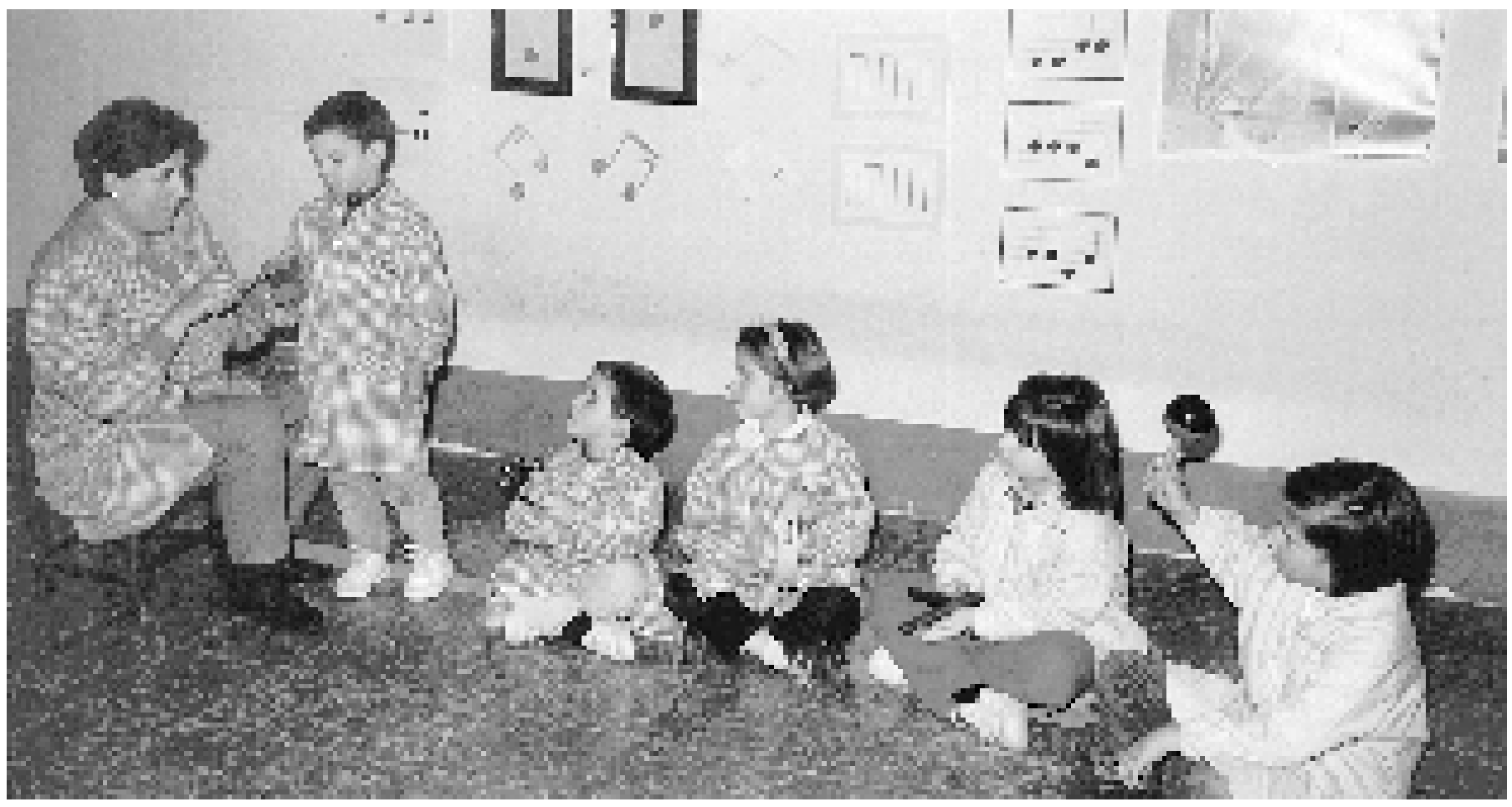

